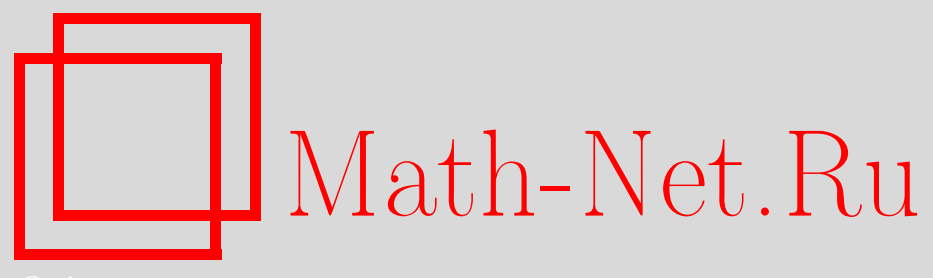

А. Минеев, Ветру и солнцу навстречу, Квант, 2019, номер 9, 2-9

DOI: https://doi.org/10.4213/kvant20190901

Использование Общероссийского математического портала Math-Net.Ru подразумевает, что вы прочитали и согласны с пользовательским соглашением http://www.mathnet.ru/rus/agreement

Параметры загрузки:

IP : 54.224 .135 .184

26 апреля 2023 г., 16:27:50 


\section{Ветру и солнцу навстречу}

\section{A.MИНEEB}

А путь и далек, и долог,

И нельзя повернуть назад.

Держись, геолог, крепись, геолог,

Ты ветра и солнца брат.

Гимн геологов XX века

ГИМНЕ ГЕОЛОГОВ ХХ ВЕКА РЕЧЬ ШЛА

об открытии геологами месторождений, главным образом, руд, металлов и невозобновляемых источников энергии нефти, газа и каменного угля, урана и тория и т.д. А ветер и солнце - «братья геолога» - в этой песне шли фоном, на котором разворачивались открытия полезных ископаемых.

B XXI веке другие вызовы. Тут уже ветер и солнце рвутся в лидеры мировой возобновляемой энергетики. Рвутся с такой силой и скоростью, что грозят потеснить и даже вытеснить со временем уголь, нефть, газ и атом с пространства энергетики. Пройдемся с ручкой и блокнотом по этому новому «возобновляемому полю» и присмотримся к цифрам и некоторым проблемам.

\section{Сколько нужно энергии?}

В настоящее время в мире проживает около 7,7 млрд человек (май 2019 г.) и на каждого в среднем тратится мощность 2,3 кВт. Общее потребление энергии приблизилось к величине $0,6 \cdot 10^{21}$ джоулей в год, или 0,6 Q/год ( $1 \mathrm{Q}=10^{21}$ Дж), или около 20 ТВт мощности $\left(2 \cdot 10^{13}\right.$ Вт).

Много это или мало? Приведенная удельная мощность средних потребностей людей на Земле (2,3 кВт/чел) складывается из бытовых энергозатрат (холодильник - 150 Вт, компьютер - 300 Вт...), затрат на транспорт, промышленность и т.д. Перепроверим еще раз указанные цифры, воспользовавшись следующей информа-

DOI: https://doi.org/10.4213/kvant20190901 цией: в 2017 году мир в целом потребил 13,5 миллиардов тонн нефтяного эквивалента (ТНЭ). Одна ТНЭ по энергии равна $4,2 \cdot 10^{10}$ Дж, а 13,5 млрд ТНЭ составит $0,57 \mathrm{Q} /$ год, или действительно около 2,3 кВт на человека.

В будущем (к 2050 г.) ожидаются увеличение населения до 10 млрд человек, некоторый рост удельной мощности потребления энергии и в результате человечеству нужно будет добывать около 1 Q / год, или непрерывно потреблять 30 ТВт мощности.

\section{Структура производства энергии из невозобновляемых и возобновляемых источников}

Сложившаяся к настоящему времени структура производства энергии и динамика ее изменения в течение последних 10 лет приведены в таблице 1. Что следует из этой таблицы?

1) Невозобновляемые ресурсы обеспечивают основную выработку энергии. Их доля сейчас более $80 \%$.

2) Доля атомной энергетики остается примерно постоянной на уровне $5 \%$.

3) Что касается возобновляемых источников энергии - ВИЭ, - то:

• больше всего энергии дает пока сжигание древесины и биомассы, но доля этого ресурса постепенно падает и сейчас составляет около $10 \%$;

- на втором месте - гидроэнергетика; этот ресурс по величине абсолютной мощности генерации практически вышел на стационар, так как районы, в которых целесообразно строить ГЭС, в основном уже освоены; сейчас она составляет 2,5\%, но по мере роста суммарного потребления энергии в мире доля гидроэнергии будет постепенно падать;

- доля ветра и солнца быстро растет, хотя пока в мировом производстве энергии она невелика; 
Таблица 1

\begin{tabular}{|c|c|c|c|}
\hline Вид энергоресурса & 2008 г. & 2018 г. & \\
\hline Нефть + газ + уголь, \% & 78 & 81 & \multirow{2}{*}{ Невозобновляемые } \\
\hline Атомная энергия, \% & 5 & 5 & \\
\hline Древесина и биомасса, \% & 13,5 & 10 & \multirow{5}{*}{ Возобновляемые } \\
\hline Гидро, \% & 3 & 2,5 & \\
\hline Ветер+солнце, \% & 0,5 & 1,5 & \\
\hline Сумма по всем ресурсам, \% & 100 & 100 & \\
\hline $\begin{array}{l}\text { Возобновляемые (древесина + био + } \\
\text { + гидро + ветер + солнце) }\end{array}$ & 17 & 14 & \\
\hline
\end{tabular}

- суммарная доля возобновляемых ресурсов (несмотря на рост доли ветра и солнца) пока снижается, главным образом из-за снижения выработки энергии из древесины и биомассы.

На этом фоне планы отдельных стран по развитию возобновляемой энергетики, приведенные в таблице 2, выглядят очень в 2020 году намечено достичь уровня генерации энергии от ВИЭ в 27\%, к 2030 году также можно ожидать 35-40\%. И даже Франция, где ядерная энергетика всегда была национальным приоритетом и ее доля в выработке энергии в недавнем прошлом достигала 75-78\%, в последнее время намечает рост доли ВИЭ до 40\% (к 2035 г.)

таблица 2

\begin{tabular}{|l|c|c|c|}
\hline \multicolumn{1}{|c|}{ Страна } & $\begin{array}{c}\text { Население, } \\
\text { млн чел. (2019 г.) }\end{array}$ & $\begin{array}{c}\text { Доля ВИЭ } \\
(2014 \text { г.) }\end{array}$ & Цель \\
\hline Германия & 80 & $28 \%$ & $80 \%$ к 2050 г. \\
\hline Дания & 5,5 & $49 \%$ & $100 \%$ к 2050 г. \\
\hline Индия & 1400 & $10 \%$ & $40 \%$ к 2030 г. \\
\hline Китай & 1400 & $9 \%$ & $27 \%$ к 2020 г. \\
\hline Франция & 65 & $18 \%$ & $40 \%$ к 2030 г. \\
\hline
\end{tabular}

амбициозно. Отдельно отметим ситуацию в Германии и Дании. Германия после аварии на АЭС в японской Фукусиме приняла решение полностью закрыть атомную генерацию у себя в стране и форсированно перейти к возобновляемым источникам энергии. В 2014 году суммарная доля ВИЭ в Германии составила уже 28\% (ветер $10 \%$, солнце $-6 \%$, гидро $-3 \%$, био $-9 \%$ ). $\mathrm{B}$ «крошечной» Дании, пионере освоения ветроэнергетики, достигли уровня ветрогенерации в 50\% и не собираются на этом останавливаться. Что касается «тяжеловесов» по населению (Индия и Китай), то Индия предполагает выйти на 40\% ВИЭ к 2030 году. Судя по тому, что в Китае уже и постепенное снижение атомной генерации до уровня 50\% (к 2035 г.).

С чем связано такое внимание к ВИЭ? Тут несколько составляющих. Во-первых - экологическая. При производстве электроэнергии с помощью возобновляемых источников энергии (ветер, солнце, гидро) отсутствуют вредные выбросы и, особенно, образование углекислого газа $\left(\mathrm{CO}_{2}\right)$, влияющего на климат и глобальное потепление. Во-вторых - ресурсная. Запасы невозобновляемых источников энергии на Земле ограничены. Ресурс же ветра и солнечной энергии весьма велик и поддерживается, пока светит наше небесное светило. 
Невозобновляемые источники энергии: ресурсы

На рисунке 1 показаны основные страны-производители и ожидаемые периоды максимума добычи этими странами нефти, газа и каменного угля. Видно, что в XXI гетики существенно выше. Есть возможность использования как уранового, так и ториевого топлива, а также сжигание топлива в реакторах на быстрых нейтронах, что еще более расширяет ресурсную базу атомной генерации. По степени влияния

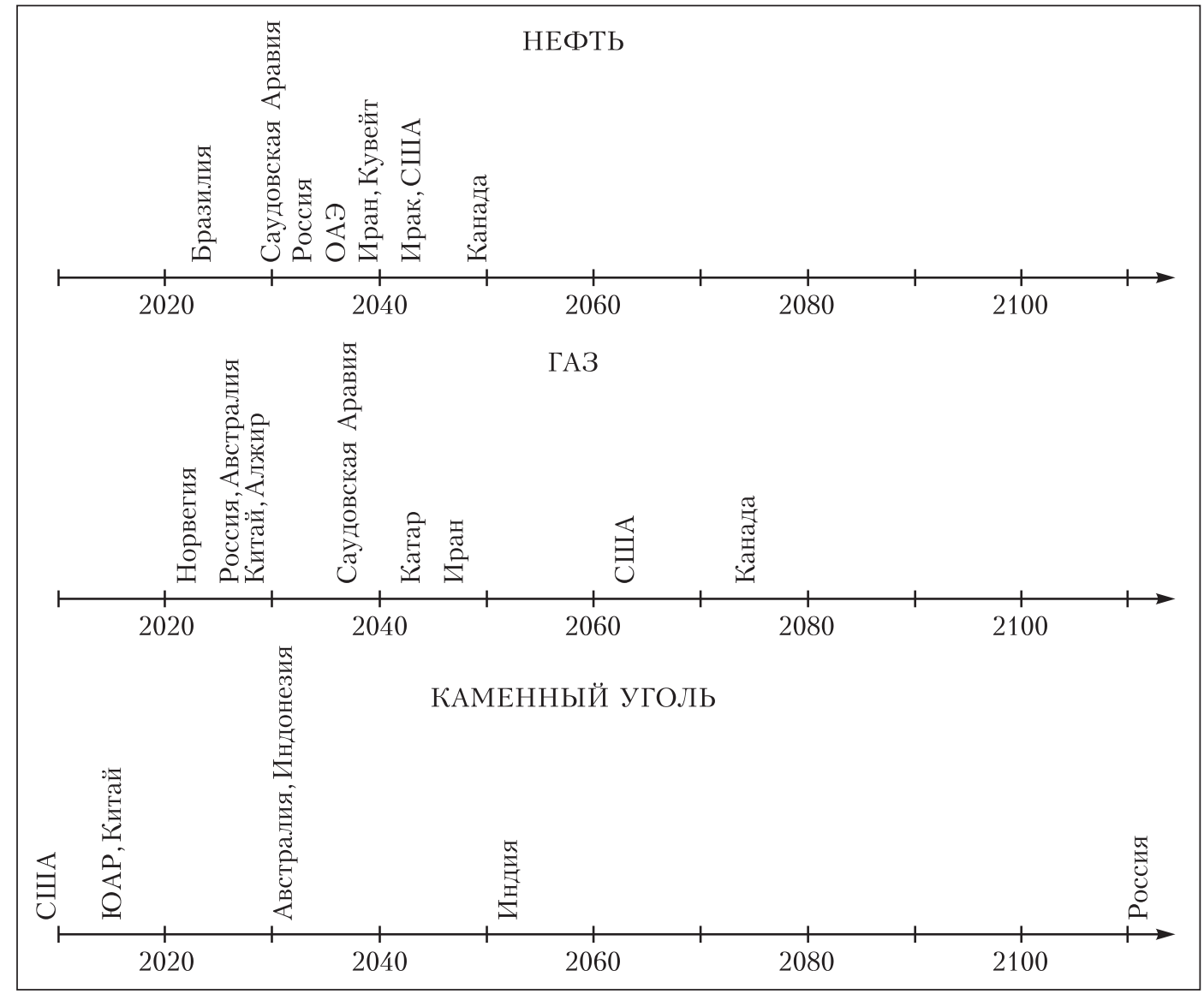

Рис. 1. Временно́е положение пиков добычи

столетии будет пройден пик добычи и должно произойти постепенное истощение запасов этих полезных ископаемых. Отметим, что пик добычи каменного угля в США, ЮАР и Китае уже миновал. Добыча нефти и газа будет снижаться уже в ближайшие десятилетия в большинстве стран, за исключением США и Канады. В сланцах (США) и битумных песках и глинах (Канада) довольно много нефти и газа, однако их извлечение вызывает серьезные экологические проблемы. В этом смысле ресурсы сырья для атомной энер- на окружающую среду из большой тройки невозобновляемых ресурсов (газ, нефть, уголь) газ является наиболее чистым, каменный уголь - наиболее грязным (выбросы электростанций на газе примерно в 2 раза меньше, чем на угле; при газовой генерации нет золы и сажи и т.д.). Газ чище, чем биотопливо. Наконец, есть еще одно важнейшее достоинство газовой генерации электроэнергии - возможность быстрой регулировки мощности, что важно при балансировке генерации энергии с ее потреблением. 


\section{Возобновляемые источники энергии, особенности генерации}

Мотором, приводящим в движение основные возобновляемые источники энергии, является излучение Солнца. Благодаря этому текут реки, дует ветер и растут растения. Энергию солнечного излучения, движения ветра, течения воды и биомассу естественно использовать для нужд человека (рис.2). Получать энергию можно также, используя тепловые процессы, происходящие в толще земной поверхности и
В раю Архимед, Паскаль и Ньютон играют в прятки. Архимед водит и начинает считать. Паскаль убегает за горизонт, а Ньютон оглядывается, берет палку, рисует вокруг себя квадрат со стороной один метр и становится внутрь квадрата. Архимед заканчивает считать, открывает глаза и видит Ньютона. - Я вижу Ньютона! - Э, нет! Ньютон на квадратный метр это Паскаль!

Мы тоже, как и в этой шутливой притче, присмотримся сначала издалека и за-
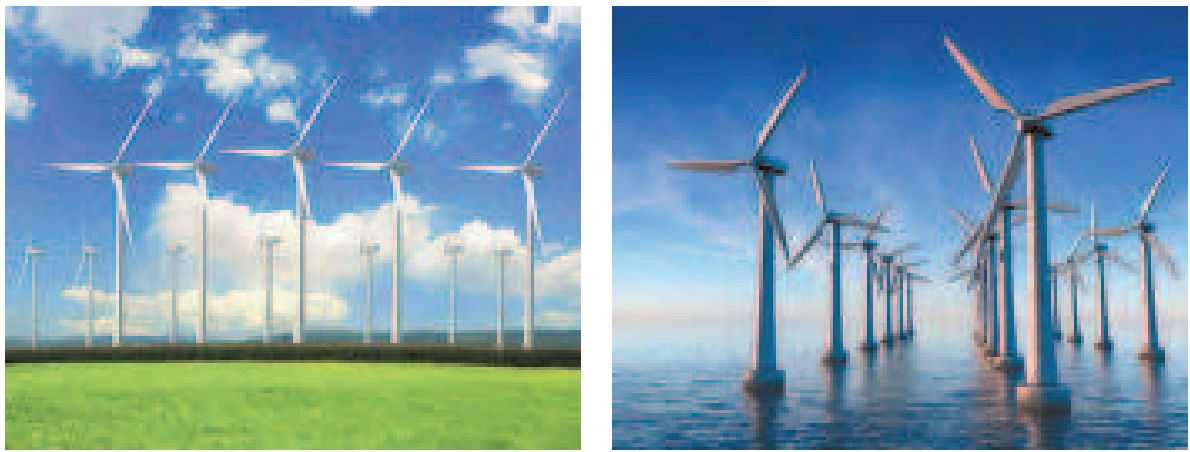

ВЭС (ветровые электростанции на суше и на море)

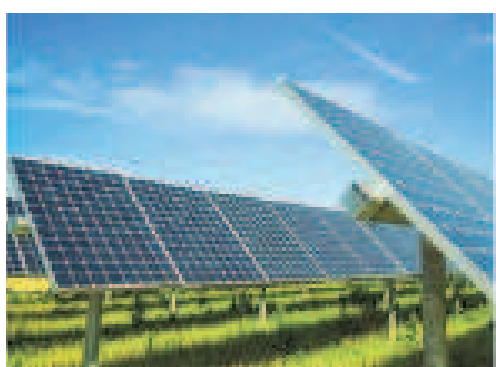

$\mathrm{CЭС}$

(солнечные электростанции)

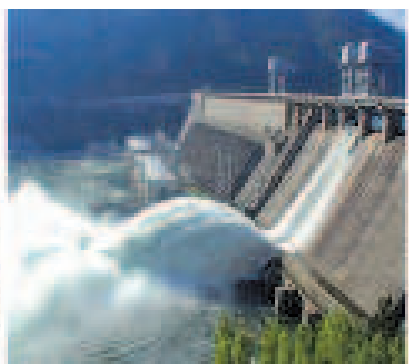

ГЭС

(гидроэлектростанции)

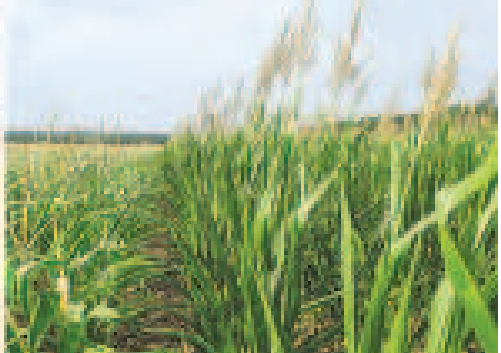

Биомасса

Рис. 2. Основные виды возобновляемых источников энергии

океанах. Эти возобновляемые источники энергии на небольшом уровне использовались испокон веков, но сейчас на наших глазах происходит революция в их применении.

Из возобновляемых источников энергии гидро и биомасса близки к насыщению, в то время как генерация с помощью ветра и солнца быстро растет. На них мы и посмотрим поближе. Навскидку - нет проблем. Известна такая притча: тем поближе, какая мощность от возобновляемых источников приходится на квадратный метр. В роли Ньютона здесь выступит Джеймс Уатт. Удельная мощность излучения Солнца вблизи орбиты Земли составляет 1,4 кВт $/ \mathrm{m}^{2}$ (солнечная постоянная). Если бы эту мощность можно было без потерь перевести в электроэнергию, то требуемые человечеству 2030 ТВт заняли бы площадь всего $(1,5-2) \cdot 10^{10} \mathrm{~m}^{2}=15000-20000 \mathrm{kм}^{2}$. Не 
так много - площадь квадрата со стороной 120-140 км.

Если не вдаваться в детали, то и с ветром похожая благоприятная картина. Действительно, мощность $N$, развиваемую вращающимися лопастями ветроагрегата, можно оценить в виде произведение силы $F$ на скорость ветра $v$ :

$$
N=F v=\frac{\rho v^{2}}{2} S v, \text { или } \frac{N}{S}=\frac{\rho v^{3}}{2},
$$

где $S$ - эффективная площадь, $\rho$ - плотность воздуха. При $\rho=1,3$ кг $/ \mathrm{m}^{3}$ и скорости ветра $v=10 \mathrm{~m} /$ с удельная мощность составляет $N / S \sim 650$ Вт $/ \mathrm{M}^{2}$ - величину того же порядка, что и солнечная постоянная.

Казалось бы все хорошо. Но если присмотреться...

Солнечная генерация. Величина электроэнергии, снимаемой с единицы площади солнечных панелей в реальных конструкuиях, оказывается на несколько порядков ниже. Причин несколько. Например:

• излучение Солнца, проходя атмосферу, приходит на поверхность Земли сильно ослабленным;

- в материале солнечной панели излучение поглощается лишь частично;

• КПД преобразования поглощенной энергии в электричество не слишком высок;

• в ночной период и при облачности излучение существенно меньше.

Что получается в итоге для реальных конструкций солнечных панелей? По данным немецких исследователей (не заинтересованных в занижении величин), характерная величина удельного энергосъема с солнечных панелей составляет всего $\sim 1 \mathrm{~B}$ / $/ \mathrm{m}^{2}$ в среднем по солнечным СЭС в мире, $\sim 5$ Вт $/ \mathrm{m}^{2}$ на территории Германии и $\sim 20 \mathrm{Bт} / \mathrm{м}^{2}$ в Сахаре. Это приводит к очень большим площадям и огромному расходу материалов. В результате при удельном энергосъеме в 5 Вт $/ \mathrm{m}^{2}$ для полной замены требуемой человечеству энергии (20-30 ТВт) с помощью СЭС требуется площадь панелей $\sim(4-6) \cdot 10^{12} \mathrm{M}^{2}=$ $=(4-6) \cdot 10^{6} \mathrm{\kappa м}^{2}$ !
Что касается материалоемкости, то приведем всего пару показательных цифр. Известно, что для обеспечения конструкции солнечных панелей требуется несколько килограммов алюминия на каждый квадратный метр их площади. Если для оценки взять 2 кг $/ \mathrm{M}^{2}$, то при площади панелей $(4-6) \cdot 10^{12} \mathrm{м}^{2}$ потребуется около $10^{10}$ тонн алюминия (!). При той же потребности в материалах каждому мегаватту электрической мощности, снимаемому с солнечной панели, соответствует 400 тонн металлоконструкций (!).

Ветровая генерация. При использовании ветра снимаемая с ветроагрегата мощность быстро растет при увеличении скорости $\left(\sim v^{3}\right)$. Однако, как и в случае солнечной генерации, есть ряд факторов, уменьшающих выход энергии с единицы площади. Так, ветроагрегаты должны располагаться на достаточном удалении друг от друга, иначе будет нарушен характер течения воздуха; площадь лопастей ветроагрегата всегда гораздо меньше заметаемой ими площади; ветроагрегаты плохо работают при очень большой и очень малой скорости воздуха.

Типичное значение удельной мощности на единицу площади земной поверхности, отчуждаемой ветроагрегатом (по данным немецких исследователей), составляет $2-3 \mathrm{BT} / \mathrm{м}^{2}$. Тот же порядок, что в случае солнечной генерации. Поэтому для полной замены требуемой человечеству энергии при использовании ветра потребуются тот же огромный уровень необходимых площадей для размещения ветроустановок, порядка $10^{13} \mathrm{~m}^{2}=10^{7} \mathrm{\kappa м}^{2}$, и тот же уровень материалоемкости. В литературе приводится такая цифра для ветряной генерации: 1 МВт соответствует 100 т стальных конструкций ветроагрегата, т.е. для полной замены требуемой энергии ветряной генерацией потребуется порядка $(2-3) \cdot 10^{9}$ тонн стальных конструкций.

В результате получается, что переход на ветер и солнце должен сопровождаться огромными затратами материалов и очень большими площадями для размещения оборудования. Причем производство этих 
материалов (не говоря уже о редкоземельных элементах, требующихся для производства солнечных батарей) не является экологичным. Не случайно Германия выводит из страны стальную и алюминиевую отрасли промышленности в страны ЮгоВосточной Азии и Восточной Европы, перемещая неэкологичные технологии в другие регионы мира. Но куда в таком случае перемещать, если все страны решат переходить на ветер и солнце?

Временной баланс потребления и генерации. На рисунке 3 приведен характерный вид кривой потребления электроэнергии в течение суток. На нем можно выде-

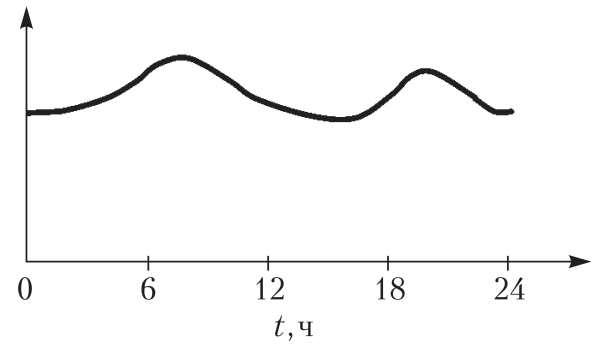

Рис. 3. Временно́й характер потребления электроэнергии

лить утренний и вечерний пики потребления (6-9 ч и 18-21 ч соответственно) и некоторый спад в дневное и ночное время. Пик производства электроэнергии при использовании солнечной генерации, при-
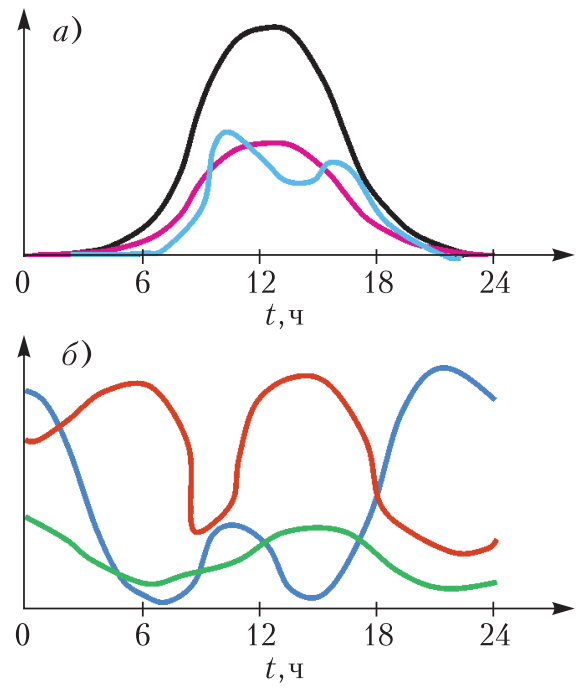

Рис. 4. Временно́й характер солнечной (а) и ветряной (б) генерации ходящийся на дневное время, приведен на рисунке 4, $a$. Черная кривая соответствует безоблачному небу, цветные - вариантам облачности. Переменчивый характер вариантов ветряной генерации показан на рисунке 4,б. Сопоставление картин поступления и потребления электроэнергии показывает, что корреляции между ними нет и соблюсти баланс в каждый момент времени при прямом использовании только солнечной и ветряной генерации невозможно.

Коэффициент использования мощности возобновляемых и невозобновляемых источников энергии. Переменный и даже непредсказуемый характер генерации энергии ветра и солнца приводит к тому, что соответствующие агрегаты используются неоптимально и коэффициент использования мощности снижается. На атомных электростанциях этот коэффициент достигает 95-98\% (в среднем он выше 80\%). Для ветроагрегатов он составляет приблизительно 17\% в среднем по Европе, 15$20 \%$ в Германии, 15\% в Китае, 25\% в США, где много территорий, на которых постоянно дуют сильные ветры. Для солнечных электростанций коэффициент использования мощности порядка $10 \%$ в Германии, $15 \%$ во Франции, 15-10\% в США. Это означает, что установленная мощность генерации ветра и солнца, т.е. та, которую можно было бы получать при оптимальных условиях, существенно превышает мощность, которая фактически вырабатывается.

\section{Что делать?}

Вернемся к таблице 2, в которой отражены планы резкого увеличения доли возобновляемых источников энергии, и попробуем нащупать пути выхода из проблем балансировки генерации и потребления электроэнергии при высоком уровне быстро меняющейся во времени доле ветряной и солнечной генерации. Из общих соображений отметим, что необходима своеобразная «основа», или «энергетическая подушка», т.е. «постоянный энергетический фон», на котором будет вырастать «надстройка» в виде перемен- 
ной ветряной и солнечной генерации. Затем нужны системы, которые могут быстро менять выдаваемую в электрическую сеть мощность, компенсируя скачки ветряной и солнечной генерации. Наконец, необходимы системы накопления излишков энергии с тем, чтобы в нужное время потратить их.

На роль «постоянного энергетического фона» идеально подходит атомная энергетика. Ее лучшие показатели соответствуют постоянной мощности генерации, поэтому нынешнюю долю (5\% в мировой энергетике) желательно не снижать, а наоборот наращивать. Подходят и энергия ГЭС, нынешний уровень которой (3\%) также уменьшать нежелательно, и использование биомассы для производства электроэнергии. Таким образом, можно обеспечить «фон» на уровне минимум $20 \%$ мирового потребления электроэнергии (лучше - еще больше).

Важной составляющей может стать газовая генерация. Она, с одной стороны, является наиболее чистой из нынешней «большой тройки» (газ, нефть, уголь). С другой стороны - запасы газа достаточно велики (в рамках XXI века). Наконец, газовые электростанции могут увеличивать постоянный «фон» производства электроэнергии и, что очень важно, позволяют легко и быстро менять выдаваемую в сеть мощность.

Варианты на основе гидроаккумулирующих электростанций - ГАЭС - также важны при покрытии пиков и спадов мощности. Согласно принципу действия, ГАЭС закачивает воду в бассейн наверх, когда есть избыток мощности, и сбрасывает воду вниз, вырабатывая электроэнергию, когда мощности не хватает.

Кроме того, использование биомассы для производства энергии тоже нельзя сбрасывать со счета. Ее можно использовать и для поддержания «фона», и для компенсации пиков потребления мощности.

А что делать, если уровень ветряной и солнечной генерации станет очень большим? В этом случае понадобятся более радикальные решения. В литературе предложен такой комплекс мер:
• создать резерв мощностей невозобновляемых источников;

- увеличить установленную мощность возобновляемых источников (запас по генерации ВИЭ);

- перекачивать мощность из регионов, где она в избытке, в те регионы, где ее не хватает (сети передачи энергии);

- аккумулировать избыточную энергию с целью ее использования во время недостаточной ветро- и солнечной генерации (накопители).

Кратко остановимся на этих мерах.

Если энергосистема основана только на ветровой и солнечной генерации, то необходим резерв невозобновляемых источников той же мощности. Фактически это приводит к дублированию устройств генерации мощности, причем каждый из элементов используется неоптимально.

Если существенно повысить установленную мощность ветро- и солнечной генерации так, чтобы даже при слабом ветре и слабом освещении энергии было достаточно, то устройств генерации потребуется гораздо больше. Было подсчитано, что при доле ветра и солнца $60 \%$ этих устройств нужно вдвое больше, при 80\% - в 6 раз больше и при 100\% - в 10 раз больше(!). Это огромный расход ресурсов, опять же используемых неэффективно.

Развитие магистральных систем передачи энергии в другие регионы требует радикального обновления сетей и увеличения их пропускной способности в 7 раз при доле ветра и солнца $60 \%$ и в 12 раз при $100 \%$. Задача очень амбициозная.

Использование накопителей или аккумуляторов энергии упрощает задачу балансировки производимой и потребляемой мощности и в принципе может позволить полностью обойтись без невозобновляемых источников энергии. Однако хранение избыточной энергии в больших масштабах сталкивается с нерешенными пока проблемами - емкостью накопителей, ресурсом, т.е. количеством циклов зарядка-разрядка, потерями при зарядке и разрядке. Кроме того, для изготовления накопителей нужно затратить довольно большое количество энергии. Так, в 
Европе при использовании в качестве накопителей литий-ионных батарей и эффективности цикла зарядка/разрядка в 85\% для производства этих батарей требуется энергия, в 15 раз (!) превышающая нынешнее годовое потребление энергии в Европе.

В последнее время очень широко обсуждается переход к так называемой водородной энергетике. Само название намекает на новый способ производства энергии. Но фактически это один из вариантов накопителя (аккумулятора) энергии, в котором сначала получают водород из воды, затрачивая энергию, затем хранят ее (в баллонах или топливных ячейках) и, наконец, высвобождают по мере надобности (например, в автомобиле).

Применительно к мировой энергетике с большой долей ветро- и солнечной генерации этот способ оказывается не слишком эффективным. Действительно, КПД получения водорода из воды составляет 65-70\%, а КПД получения электричества из водорода $\sim 50 \%$. Таким образом, суммарный КПД составляет всего 30-35\%, т.е. большая часть энергии выбрасывается на ветер. В то же время использование водорода как вида топлива (в транспорте) в принципе может стать реальной заменой нефти, запасы которой весьма ограничены.

$$
* * *
$$

В итоге развитию возобновляемых источников энергии сейчас придан большой импульс. Уровень затрат на ветро- и солнечную генерацию превысил один триллион долларов (!). По мере роста доли ВИЭ появились проблемы и факторы, сдерживающие ее развитие: дублирование мощностей, управляемость, сети и потери в сетях, ресурс оборудования, медленное развитие накопителей, КПД накопителей, низкий коэффициент использования мощности. Ближайшие 10-20 лет покажут, насколько реальны планы и амбиции, как удастся решить проблемы и каким окажется на деле уровень ВИЭ в мире.

При подготовке статьи использовались данные А.Анпилогова, С.Безгина и Д.Станкевича.

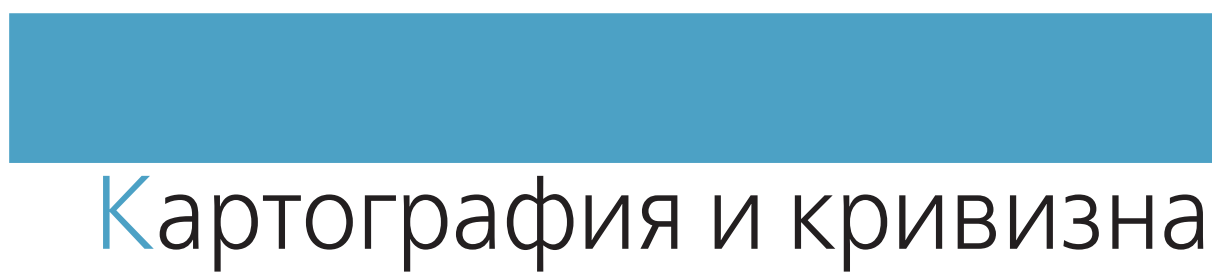

И.ТАЙМАНОВ

\section{РДАЧА О ПОСТРОЕНИИ НАИБОЛЕЕ \\ точной или удобной для использования} карты земной поверхности известна с давних времен. Отображение земной поверхности (или части ее) на плоскость называется картографической проекцией (картой) и сопоставляет точке поверхности точку на плоскости.

Понятия долготы и широты ввел в начале II века нашей эры древнегреческий математик и географ Марин Тирский для

DOI: https://doi.org/10.4213/kvant20190902 того, чтобы построить с их помощью карту, которая сохраняет масштаб длин вдоль экватора и всех меридианов. Эта прямоугольная карта строится очень просто: обозначим через $\lambda$ долготу, а через $\varphi$ широту; если точка с координатами $\left(\lambda_{0}, \varphi_{0}\right)$ отображается в точку $(0,0)$, то точка с координатами $(\lambda, \varphi)$ отображается в точку плоскости с координатами $x=\lambda-\lambda_{0}$, $y=\varphi-\varphi_{0}$. Такая проекция (рис.1) называется равнопромежуточной и до сих пор используется, например, в геоинформационных системах. При ней не сохраняются 